\title{
BỆNH LAO KHÁNG RIFAMPICIN TẠI THÁI NGUYÊN
}

\author{
Hoàng Hà*, Lưu Thị Thu Uyên*, Ngô Thị Hoài*
}

\section{TÓM TẮT}

Mục tiêu: mô tả đặc điểm lâm sàng và phân tích một số yếu tố liên quan đến kết quả điều trị RR-TB. Phương pháp: nghiên cứu mô tả, thời gian từ 2016 - 2020 tại Bệnh viện Lao và bệnh Phổi Thái Nguyên. Chon mẫu toàn bồ bênh nhần xét nghiêm Xpert MTB/RIF có RR-TB điều trị phác đồ chuẩn 11 tháng 4$6 \mathrm{Km}$ Lfx Pto CfZ Z H liều cao E/5 Lfx CfZ Z E. Kết quả: có $948 / 4187(22,6 \%)$ MTB/RIF (+), thu được $83 / 948(8,8 \%)$, RR-TB có nguồn là thể lao mới chiếm $27 / 675(4 \%) ;$ thể lao cũ là $43 / 215(20 \%)$ và thể lao ngoài phổi là $13 / 58(1,2 \%)$. Có 60 (72,3\%) RR-TB điêu trị phác đồ 11 tháng. Kết quả điều trị tốt đạt 48 $(80 \%)$ và kém là $12(20 \%)$. Kết luân: RR-TB thường gặp nhiều ở nhóm tuổi trung niên, thể lao cũ, soi đờm có $\mathrm{AFB}(+)$, tổn thương Xquang Phổi rộng. Các yếu tố ảnh hưởng kém đến kết quả điều trị RR-TB là: thể lao cũ, khám phổi có ran, soi đờm có AFB $(+)$, Xquang Phổi có hang.

Tư khóa: Bênh Lao, Kháng thuốc, Đa kháng thuốc, Xpert mtb/rif, Thái Nguyên.

Chữ viêt tăt. Kháng rifampicin (RR); Đa kháng thuốc (MDR); Bệnh Lao (TB);isoniazid (H); streptomycin (S); rifampicin (R); ethambutol (E); pyrazinamid $(\mathrm{Z})$; kanamycin $(\mathrm{Km})$; p-aminosalicylic acid (PAS); amikacin(Am); $\operatorname{cpreomycin}(\mathrm{Cm})$; levofloxacin(Lfx); moxiloxacin(Mfx); protiolamide (Pto); cyclocerine(Cs); bedaquyline(Bdq); clofazimine(Cfz); linezolid(Lzd).

\section{SUMMARY \\ RIFAMPICIN RESISTANT TUBERCULOSIS IN THAI NGUYEN}

Objectives: to characterize the clinical situation and analyze a number of factors related to treatment outcomes for RR-TB. Methods: Descriptive study at Thai Nguyen Hospital of Tuberculosis and Lung Disease, from 2016 - 2020. Sample of all patients tested for Xpert MTB / RIF with RR-TB on standard regimen 11 months 4-6 Km Lfx Pto $\mathrm{CfZ} Z \mathrm{ZH}$ high dose $\mathrm{E}$ / 5 Lfx Cfz Z E. Results: 948/4187 (22.6\%) Mtb / Rif $(+)$, obtained $83 / 948(8.8 \%)$, RR-TB sourced the new TB form was $27 / 675$ (4\%); The previous antiTB treatment form was $43 / 215(20 \%)$ and the extrapulmonary form was $13 / 58(1.2 \%)$. There were $60(72.3 \%)$ RR-TB on the 11-month regimen. Good outcome of treatment is $48(80 \%)$ and poor is 12 $(20 \%)$. Conclusions: RR-TB was more common in the middle-aged group, previous antiTB treatment, (AFB) smear-positive sputum, extensive lung X-ray lesions. Factors that affect poorly on treatment

*Trường ĐHYD Thái Nguyên

Chịu trách nhiệm chính: Hoàng Hà

Email: hoangha@tnmc.edu.vn

Ngày nhận bài: 2/1/2021

Ngày phản biện khoa học: 1/2/2021

Ngày duyệt bài: 3/3/2021 outcomes were: previous antiTB treatment, rales in lungs sound, smear-positive sputum and cavitary disease.

Keywords: Tuberculosis, Drug resistance, Multiple drug resistance, Gene Xpert mtb / rif, Thai Nguyen.

\section{I. ĐĂT VẤN ĐỀ}

Xác định bệnh lao kháng rifampicin (RR-TB) chủ yếu bằng kỹ thuật XpertMTB/RIFbởi các phòng xét nghiệm chuyển khoa tuyến tỉnh, trong đó có Thái Nguyên. Điều tra cho thây có đến 3/4 các chủng vi khuẩn lao kháng rifampicin thì có kháng cả isoniazid, nên có tên lao đa kháng hoặc lao kháng rifampicin (MDR/RR-TB).

Hiện nay, trên thế giới có 500.000trường hợp RR-TB, trong đó có $78 \%$ mắc MDR-TB.Số mắc MDR/RR-TB chiếm 3,4\% trong số lao mới và $18 \%$ trong số lao đã điêu trị.

Việt Nam nằm trong nhóm 27 quốc gia có gánh nặng lao kháng thuốc cao nhất thế giới, xếp thứ $11 / 20$ quốc gia có số lượng bệnh nhân MDR-TB nhiều nhất, chiếm 1,7\% toàn cầu.

Phát hiện, quản lý điều trị MDR/RR-TB khó khăn và phức tạp hơn thể lao thông thường do có nhiều sự khác nhau về lâm sàng, vì phảiđiều trị bằng các thuốc hàng haicó nhiều tác dụng phụ, thời gian kéo dài hơn vàchi phí cũng tăng lên rất nhiều.

Nghiên cứu RR-TB là rất cân thiết, nhưng tai Thái Nguyên còn mới và có ít đề tài. Chúng tổi tiến hành nghiên cứu này nhằm các mục tiêu sau:

1) Mô tả đặc điểm lâm sàng, xét nghiệm của $R R-T B$.

2) Phân tích một số yếu tố liên quan đên kêt quả điều trị RR-TB.

\section{II. ĐỐI TƯƠNG VÀ PHƯƠNG PHÁP NGHIÊN CỨU}

2.1.Đối tượng, thời gianvà địa điểm nghiên cứu. Nghiên cứu tiến hành tại Bệnh viện Lao và bệnh Phổi (L\&BP) Thái Nguyên, từ 1/2016-12/2020. Bao gồm tất cả các bệnh nhâncó chỉ định thử nghiệm XpertMTB/RIF theo hướng dẫn của CTCLQG.

2.2.Phương pháp nghiên cứu: nghiên cứu mô tả, thiết kế hồi cứu và tiến cứu. Cõ̃ mẫu toàn bộ.

\subsection{Chỉ tiêu nghiên cứu}

- Chỉ tiêu về các tỷ lệ RR-TB

- Chỉ tiêu chung của RR-TB: tuổi, giới, địa chỉ, nghề nghiệp, tiền sử bệnh.

- Nhóm chỉ tiêu về đặc điểm lâm sàng, xét nghiệm của RR-TB

- Chỉ tiêu kết quả điêuu trị và các yếu tố liên quan với kết quả điều trị RR-TB theo phác đồ 11 tháng. 
2.4. Tiêu chuẩn, kỹ thuật và phác đồ điêuu trị trong nghiên cứu

- Xét nghiệm tìm AFB theo nguyên lý vi khuẩn kháng axit giữ màu carbol fuchsin nên chúng xuất hiện màu đỏ. Bệnh phẩm đờm được dàn trên lam kính và nhuộn soi trực tiếp trên kính hiển vi theo phương pháp Ziehl Neelssen.

- Xét nghiệm GeneXpert dựa trên 3 công nghệ: (1)Tách gen là vi khuẩn bị tiêu hủy bởi sóng siêu âm mạnh.ADN của vi khuẩn sẽ được chiết tách và có hệ thống tự kiểm định chất lượng quá trình chiết tách; (2)Nhân gen (khuyếch đại gen) bằng kỹ thuật Realtime hemi - nested PCR; và (3)Xác định gen bằng phát hiện các đoạn gen đặc hiệu của vi khuẩn lao và tính kháng rifampicin của vi khuẩn. Bệnh phẩm là đờm của bệnh nhân được hướng dẫn lấy đúng cách.

- Bệnh lao kháng thuốc rifampicin (RR-TB) là tình trạng vi khuẩn lao kháng tối thiểu thuốc rifampicin được xác định bằng thử nghiệm Genexpert.

-Chỉ định Phác đồ chuẩn 11 tháng theo CTCLQG. Công thức phác đồ 4-6 Km Lfx Pto Cfz Z H liều cao E/5 Lfx Cfz Z E. Giai đoạn tấn công kéo dài 4-6 tháng bao gồm các loại thuốc: $\mathrm{Km}$, Lfx, Pto, Cfz, Z, H. [1]. Quản lý điều trị giai đoạn nội trú thực hiện thăm khám lâm sàng hàng ngày tại giường bệnh. Giai đoạn ngoại trú cho tái khám hằng ngày tại y tế cơ sở, khám lâm sàng, theo dõi đáp ứng điều trị, theo dõi biến chứng bệnh và tác dụng phụ của thuốc, theo dõi các xét nghiệm, chụp X-quang và thăm khám cần thiết khác.

- Nhận định kết quả điều trị theo hướng dẫn của BYT 2018 [1]:

+ Kết quả tốt là điều trị thành công bao gồm hai nhóm (1) Khỏi: Hoàn thành liệu trình điều trị và không có bằng chứng thất bại, đồng thời có ít nhất 2 mẫu nuôi cấy âm tính liên tiếp cách nhau ít nhất 30 ngày ở cuối giai đoạn duy trì; (2) Hoàn thành điêuu trị: Hoàn thành liệu trình điêu trị và không có bằng chứng thất bại, tuy nhiễn không ghi nhận đủ thông tin có ít nhất 2 mẫu nuôi cấy âm tính liên tiếp cách nhau ít nhất 30 ngày ở cuối giai đoạn duy trì.

+ Kết quả kém là các nhóm còn lại gồm bốn nhóm: (1) Thất bại: không âm hóa cuối giai đoạn tấn công kéo dài, hoặc dương tính trở lại trong giai đoạn duy trì sau khi đã âm hóa, hoặc ngừng điều trị ít nhất 2 trong các thuốc bổ sung $(\mathrm{E}, \mathrm{Z}, \mathrm{H})$, hoặc ít nhất 1 trong các thuốc chủ đạo (FQ, SLI, Pto/Eto, Cfz) vì lý do phản ứng bất lợi hoặc phát hiện kháng thuốc; (2) Chết: người bệnh chết do bất cứ nguyên nhân nào trong quá trình điều trị lao kháng thuốc; (3) Không theo dõi được: người bênh ngừng điêuu trị liên tục từ 2 tháng trở lên do bất cứ lý do gì; (4) Không đánh giá: người bệnh không được đánh giá kết quả điều trị (bao gồm cả các trường hợp chuyển đến đơn vị điều trị khác và các trường hợp không biết kết quả điều trị) [1].

\section{Sơ đồ nghiên cứu và chọn mẫu điều trị phác đồ 11 tháng}

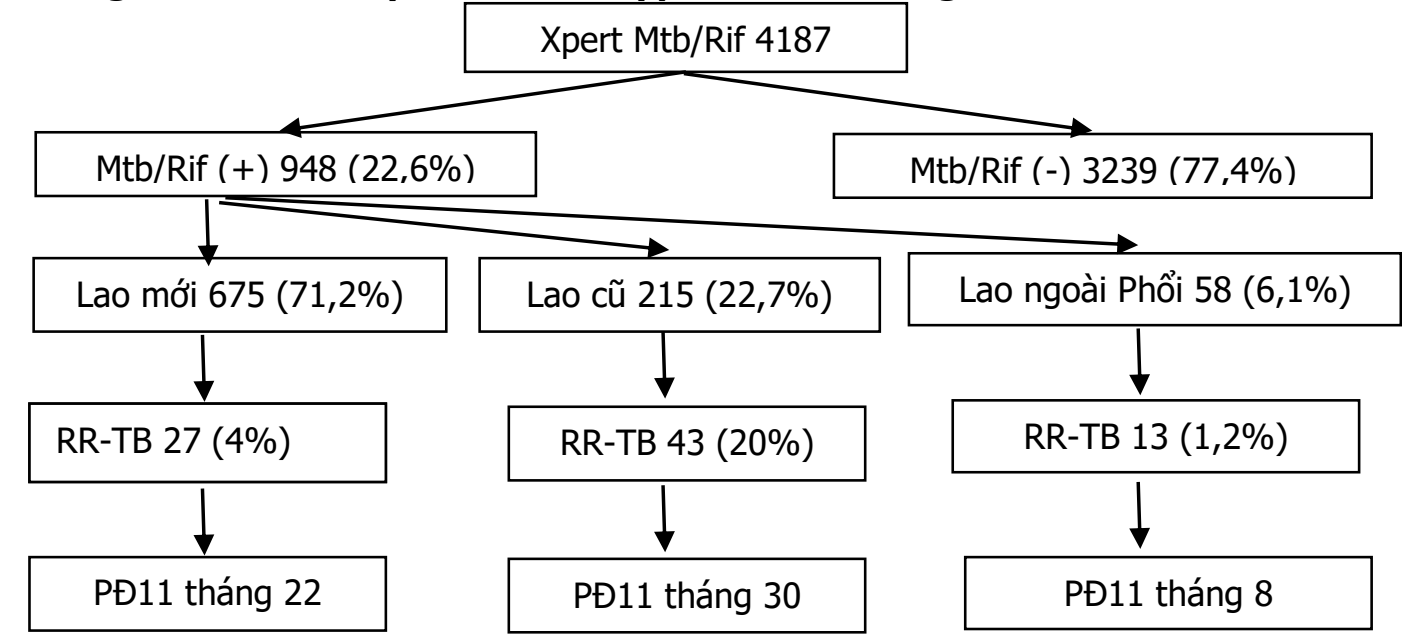

2.5.Phương pháp thu thâp xử lí số liêu: Thông tin hồi cứu và tiến cứu được ghi vào bệnh án nghiên cứu mẫu. Số liệu nhập và xử lý trên phần mềm SPSS 20.0.

2.6. Đạo đức nghiên cứu: Hồ sơ nghiên cứu được thông qua Hội đồng đạo đức Trường
Đai học Y Dược Thái Nguyên, được sự chấp thuận của Bệnh viện L\&BP Thái Nguyên.

\section{KẾT QUẢ NGHIÊN CứU \\ Bảng 1: Đặc điểm chung của bệnh nhân $R R-T B$}




\begin{tabular}{|c|c|c|c|}
\hline \multicolumn{2}{|c|}{ Nhóm tuổi } & $\begin{array}{c}\text { Số lượng } \\
(\mathbf{n = 8 3 )}\end{array}$ & $\begin{array}{c}\text { Tỷ lệ } \\
(\mathbf{\%})\end{array}$ \\
\hline \multicolumn{2}{|c|}{$15-30$} & 14 & 16,9 \\
\hline \multicolumn{2}{|c|}{$31-45$} & 31 & 37,3 \\
\hline \multicolumn{2}{|c|}{$45-60$} & 27 & 32,5 \\
\hline \multicolumn{2}{|c|}{$>60$} & 11 & 13,3 \\
\hline \multirow{2}{*}{ Tuổi trung bình } & $\begin{array}{c}42,6 \pm \\
13,67\end{array}$ & $\begin{array}{l}\text { Min=17, } \\
\text { Max }=72\end{array}$ \\
\hline \multirow{2}{*}{ Giới } & Nam & 68 & 81,9 \\
\cline { 2 - 4 } & Nữ & 15 & 18,1 \\
\hline \multirow{2}{*}{$\begin{array}{c}\text { Nghề } \\
\text { nghiệp }\end{array}$} & Phạm nhân & 8 & 9,6 \\
\cline { 2 - 4 } & Nống dân & 61 & 73,5 \\
\cline { 2 - 4 } & Viên chức & 14 & 16,9 \\
\hline \multirow{2}{*}{ Nhân }
\end{tabular}

Nhận xét: Tuối bênh nhân RR-TB thường gặp là $31-60$, chiếm $(79,8 \%)$. Tuổi trung bình của bệnh nhân là 42,6 $\pm 13,67$ tuổi. Tỷ lệ mắc ở giới nam $(81,9 \%)$ cao hơn nữ $(18,1 \%)$. Bệnh nhân là nông dân chiếm chủ yếu là $73,5 \%$, số bệnh nhân là phạm nhân chiếm đáng kể là $9,6 \%$.

Bảng 2: Đặc điểm triệu chứng lâm sàng

\begin{tabular}{|c|c|c|}
\hline Triệu chứng & $\begin{array}{c}\text { Số lượng } \\
(\mathbf{n = 8 3}\end{array}$ & $\begin{array}{c}\text { Tân suất } \\
\mathbf{( \% )}\end{array}$ \\
\hline Ho khạc đờm kéo dài & 77 & 92,8 \\
\hline Sốt nhẹ về chiều & 59 & 71,1 \\
\hline Gầy sút cân & 64 & 77,1 \\
\hline Mệt mói, chán ăn & 59 & 71,1 \\
\hline Ho ra máu & 10 & 12,0 \\
\hline Đau tức ngực & 50 & 60,2 \\
\hline Khó thở & 46 & 55,4 \\
\hline Sốt cao & 10 & 12,0 \\
\hline Phối có ran & 47 & 56,6 \\
\hline
\end{tabular}

Nhận xét: Bệnh nhân có triệu chứng ho khạc đờm kéo dài chiếm tỷ lệ cao nhất 92,8\%. Các triêu chứng sốt nhẹ về chiêu, gây sút cân, mệt mỏi chán ăn chiếm tỷ lệ lần lượt là: $71,1 \% ; 77,1 \%$ và $71,1 \%$. Ho ra máu chiếm $12 \%$, đau tức ngực chiếm $60,2 \%$ và phổi có ran chiếm tỷ lệ $56,6 \%$.

Bảng 3: Đặc điểm một số xét nghiệm cận lâm sàng

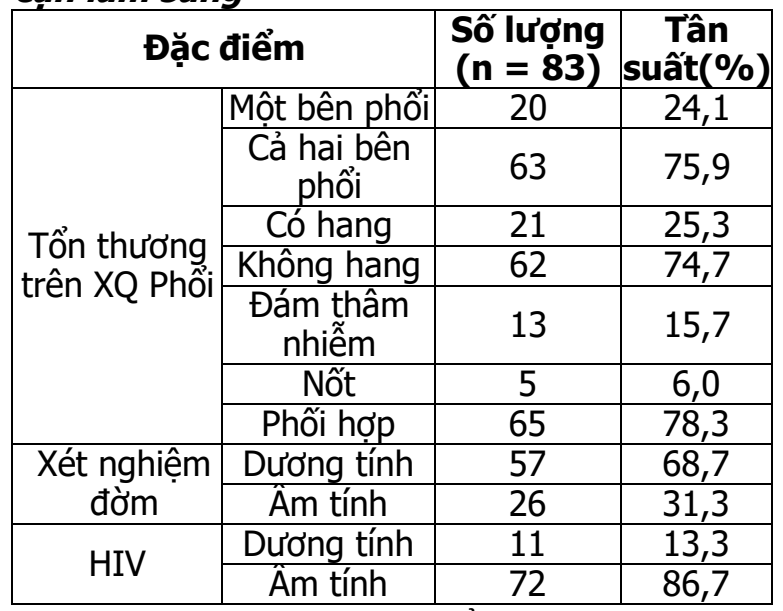

Nhận xét: Hình ảnh tổn thương trên $X-$ quang phổi: Tổn thương một bên chiếm 24,1\%, tổn thương cả hai bên phổi $(75,9 \%)$; có tổn thương hang chiếm 25,3\%; tổn thương đám thâm nhiễm chiếm $15,7 \%$; tổn thương nốt chiếm $6 \%$ và tổn thương phối hợp chiếm 78,3\%.

Xét nghiệm AFB dương tính chiếm 68,7\%, âm tính chiếm $31,3 \%$

Xét nghiệm HIV dương tính chiếm 13,3\%.

Bảng 4: Môi liên quan giữa đặc điểm lâm sàng, xét nghiệm và kêt quả điều trị

\begin{tabular}{|c|c|c|c|c|c|}
\hline \multicolumn{2}{|c|}{ Đặc điểm } & $\begin{array}{l}\text { KQ kém } \\
(\mathrm{n}=12)\end{array}$ & $\begin{array}{c}\text { KQ Tốt } \\
(\mathrm{n}=48)\end{array}$ & $\begin{array}{c}\text { Tống } \\
\text { n (\%) }\end{array}$ & $x 2, p$ \\
\hline \multirow{2}{*}{ Giới } & Nam & $11(18,3)$ & $37(61,7)$ & $48(80,0)$ & \multirow{2}{*}{$\begin{array}{c}1,28 \\
>0,05\end{array}$} \\
\hline & Nữ & $1(1,7)$ & $11(18,3)$ & $12(20,0)$ & \\
\hline \multirow{2}{*}{ Ho ra máu } & Có HRM & $4(6,7)$ & $4(6,7)$ & $8(13,3)$ & \multirow{2}{*}{$\begin{array}{r}5,20 \\
<0,05 \\
\end{array}$} \\
\hline & Không HRM & $8(13,3)$ & $44(73,3)$ & $52(86,7)$ & \\
\hline \multirow{2}{*}{ Phổi có ran } & Có ran & $11(18,3)$ & $23(38,3)$ & $34(56,7)$ & \multirow{2}{*}{$\begin{array}{r}7,48 \\
<0,01 \\
\end{array}$} \\
\hline & Không có & $1(1,7)$ & $25(41,7)$ & $26(43,3)$ & \\
\hline \multirow{3}{*}{ Thể lao } & Mới & $2(3,3)$ & $20(33,3)$ & $22(36,7)$ & \multirow{3}{*}{$\begin{array}{c}2,60 \\
>0,05\end{array}$} \\
\hline & Cũ & $8(13,3)$ & $22(36,7)$ & $30(50,0)$ & \\
\hline & Khác & $2(3,3)$ & $6(10,0)$ & $8(13,3)$ & \\
\hline \multirow{2}{*}{ AFB } & $(+)$ & $11(18,3)$ & $30(50,0)$ & $41(68,3)$ & \multirow{2}{*}{$\begin{array}{c}3,77 \\
>0,05 \\
\end{array}$} \\
\hline & $(-)$ & $1(1,7)$ & $18(30,0)$ & $19(31,7)$ & \\
\hline \multirow{2}{*}{ HIV } & $(+)$ & $5(8,3)$ & $4(6,7)$ & $9(15,0)$ & \multirow{2}{*}{$\begin{array}{r}8,37 \\
<0,01 \\
\end{array}$} \\
\hline & $(-)$ & $7(11,7)$ & $44(73,3)$ & $51(85,0)$ & \\
\hline \multirow{2}{*}{$\begin{array}{l}\text { Vị trí tốn } \\
\text { thương }\end{array}$} & Một bên & $4(6,7)$ & $9(15,0)$ & $13(21,7)$ & \multirow{2}{*}{$\begin{array}{r}1,20 \\
>0,05 \\
\end{array}$} \\
\hline & Hai bên & $8(13,3)$ & $39(65,0)$ & $47(78,3)$ & \\
\hline \multirow{2}{*}{$\begin{array}{c}\text { Tốn thương } \\
\text { hang }\end{array}$} & Có & $6(10,0)$ & $10(16,7)$ & $16(26,7)$ & \multirow{2}{*}{$\begin{array}{c}4,18 \\
<0,05 \\
\end{array}$} \\
\hline & Không & $6(10,0)$ & $38(63,3)$ & $44(73,3)$ & \\
\hline
\end{tabular}

Nhận xét: Bệnh nhân không ho ra máu $(73,3 \%)$ có kết quả điều trị tốt nhiêu hơn rõ rệt 
$(63,3 \%)$ có kết quả điều trị tốt nhiều hơn rõ rệt so với bệnh nhân XQ Phổi có hang $(16,7 \%)$, với $\mathrm{p}<0,05$. Bệnh nhân HIV (-) $(85 \%)$ có kết quả điều trị tốt nhiều hơn so với bệnh nhân HIV $(+)$ $(13,3 \%)$, với $p>0,05$.

Bệnh nhân khám phổi có ran $(18,3 \%)$ có kết quả điều trị kém nhiêu hơn rõ rệt so với bệnh nhân khám phổi không có ran $(1,7 \%)$, với $p<$ 0,01 . Bệnh nhân có $A F B(+)(18,3 \%)$ có kết quả điêu trị kém nhiều hơn so với bệnh nhân có AFB $(-)(1,7 \%)$, với $p>0,05$, chưa có ý nghĩa thống kê. Bệnh nhân thể lao cũ $(13,3 \%)$ có kết quả điều trị kém nhiều hơn so với bệnh nhân thể lao mới $(3,3 \%)$, với p> 0,05, chưa có ý nghĩa thống kê.

\section{BÀN LUÂN}

4.1. Một số đặc điểm chung của RR - TB. Phân bố tuổi của các bệnh nhân gặp nhiều ở nhóm từ 31 - 60 tuổi, chiếm 69,8\% nhiều hơn so với các nhóm tuổi khác. Nhóm bệnh nhân $<20$ tuổi và $>60$ tuổi chiếm tỷ lệ thấp cùng là $<20 \%$. Nhóm tuổi $30-50$ gặp thể lao điều trị lại nhiêu hơn nhóm tuổi khác. Bởi vì ở bệnh nhân lao, khi tuổi tăng đến già bao nhiều thì sẽ giảm cớ hội điêu trị lại bây nhiêu. Ngược lại ở người trẻ mắc lao, phải có quãng thời gian nhất định để mắc bệnh lại, khi đó tuổi của họ cũng là khoảng từ 31 - 60. Kết quả về nhóm tuổi của nghiên cứu này tương đương với nghiên cứu của Nguyễn Bình Hòa và Cs (2015) tại Bệnh viện Phạm Ngọc Thạch nghiên cứu trên 282 bệnh nhân MDR - TB cho thây nhóm tuổi gặp nhiều nhất là 30- 45 (58,2\%). Tuổi trung bình của bệnh nhân ở nghiên cứu này là $42,6 \pm 13,67$. Đó là tuổi khá thường gặp, và cũng tương đương với nghiên cứu của Mahmood Iqbal Malik 2019, có tuổi bệnh nhânlao kháng thuốc trung bình là 48,25 \pm 18,21 [3]. Tỷ lệ bệnh nhân nam $(81,9 \%)$ cao hớn nữ $(18,1 \%)$. Kết quả này là phù hợp trên thế giới, theo WHO Report, các quốc gia đều có tỷ lệ bệnh lao ở nam giới cao hơn nữ giới, ngoại trừ Bangladesh và Pakistan [6].

Nghề nghiệp của bệnh nhân làm nông nghiệp chiếm tỷ lệ cao nhất là $73,5 \%$. Nghề nông nghiệp có tỷ lệ bệnh cao rất có thể do người dân làm nghề nông thường có thu nhập thấp, đời sống chưa đảm bảo, họ thường xuyên phải đối mặt với rất nhiều khó khăn trong cuộc sống hàng ngày. Sự thiếu thốn về kinh tế, vật chất sẽ tác động đến sức khoẻ cũng như khả năng đề kháng không mắc lao của người dân. Số bệnh nhân phạm nhân chiếm $9,6 \%$ là rất đáng quan tâm, vì theo CTCLQG phạm nhân là nguy cơ tiềm tàng lây nhiễm bệnh MDR/RR - TB.
4.2 Triệu chứng lâm sàng, cận lâm sàng của RR - TB. Triệu chứng lâm sàng cơ bản của RR-TB là tương tự như lao phổi, ba triệu chứng thường gặp là ho kéo dài chiếm cao nhất sau đó đến sốt nhe về chiều, gầy sút cân với tần suất lần lượt là: $92,8 \%, 71,1 \%$ và $71,1 \%$.

Một số triệu chứng khác xuất hiện nhiều hơn thể lao phổi thông thường với khác biệt ít. Đó là ho ra máu chiếm $12 \%$, đau tức ngực chiếm $60,2 \%$ và phổi có ran chiếm tỷ lệ $56,6 \%$. Đây là những triệu chứng xuất hiện nhiều ở bệnh nhân thể lao cũ, bệnh tái lại, tổn thương xơ sẹo nhiều, vì có $43 / 83(51,8 \%)$ là thể lao cũ đưa vào nghiên cứu (sơ đồ nghiên cứu).

Trong số 83 RR-TB xét nghiệm đờm tìm AFB, đương tính chiếm $68,7 \%$, và âm tính là $31,3 \%$ là. Kết quả cho thấy sử dụng xét nghiệm Xpert MTB/RIFsẽ làm tăng khả năng phát hiện và xác định lao. Nghiên cứu của Grace Moraa Orina tại Kenya 2017, cho thấy xét nghiệm soi đờm tìm AFB có kết quả dương tính thấp hơn so với GeneXpert MTB/RIF với tỷ lệ tương ứng là $7,01 \%$ và $19,65 \%$ [4].

Tổn thương haibên phổi có tỷ lệ cao nhất (75,9\%), tổn thươngmộtbên phổi chiếm tỉ lệ thấp $24,1 \%$, tổn thương có hang là $25,3 \%$, tổn thương phối hợp là 78,3\%.Các đặc điểm tổn thương $X$ quang Phổi nêu trên cho thấy phù hợp với diển tiến của thể lao cũ, có tổn thương rộng, có sự hoạt động lại trên nền tổn thương cũ.

Số mẫu thử nghiệm Xpert trong nghiên cứu là 4187, kết quả có $\operatorname{MTB} / R \operatorname{RIF}(+)$ là $948(22,6 \%)$. Số RR-TB là $83 / 948(8,8 \%)$, trong đó thể lao mới RR-TB có $27 / 675$ (4\%); thể lao cũ RR-TB có $43 / 215(20 \%)$ và thể lao ngoài phổi RR-TB có $13 / 58(1,2 \%)$. Tỷ lệ RR-TB trong thể lao cũ nhiều hơn lao mới là do đã điều trị thuốc lao hàng một có rifampicin. Tỷ lệ cao này cũng phù hợp với báo cáo của cả nước 2019, lần lượt là $1,3 \%$ và $17 \%$; của WHO $2019,3,4 \%$ và $18 \%$ [6]. Khi xét tỳ lệ lao cũ trong số RR-TB cũng thấy rất cao $43 / 83(51,8 \%)$, kết quả này cũng phù hợp với báo cáo của WHO 2019, tỷ lệ đó là cao nhất, và $>50 \%$ [6]

4.2. Kết quả điêu trị và mối liên quan. Nghiên cứu gồm60 $(72,3 \%)$ trong 83 bệnh nhân RR-TB điều trị phác đồ lao kháng thuốc chuẩn 11 tháng, trong đó thể lao mới là 22; lao cũ 30 và lao ngoài phổi 8 . Kết quả điều trị tốt đạt 48 $(80 \%)$ và kém là $12(20 \%)$. Kết quả này là tốt và phù hợp khi so với một số nghiên cứu điều trị lao kháng thuốc. Theo WHO, dữ liệu kết quả điều trị mới nhất cho những người bịMDR / RRTB cho thấy tỷ lệ điều trị thành công trên toàn 
câu là 56\%.

Bệnh nhân không ho ra máu $(73,3 \%)$ có kết quả điêu trị tốt nhiều hơn rõ rệt so với bệnh nhân có ho ra máu $(6,7 \%)$, với $p<0,05$. Bệnh nhân XQ Phổi không có hang $(63,3 \%)$ có kết quả điêuu trị tốt nhiều hơn rõ rệt so với bệnh nhân XQ Phổi có hang $(16,7 \%)$, với $p<0,05$. Bệnh nhân HIV (-) $(85 \%)$ có kết quả điều trị tốt nhiều hơn so với bệnh nhân HIV $(+)(13,3 \%)$, với p> 0,05, chưa có ý nghĩa thống kê.

Bệnh nhân khám phổi có ran $(18,3 \%)$ có kết quả điều trị kém nhiều hơn rõ rệt so với bệnh nhân khám phổi không có ran $(1,7 \%)$, với $\mathrm{p}<$ 0,01 . Bệnh nhân có AFB (+) $(18,3 \%)$ có kết quả điều trị kém nhiều hơn so với bệnh nhân có $A F B$ (-) $(1,7 \%)$, với $p>0,05$, chưa có ý nghĩa thống kê. Bệnh nhân thể lao cũ $(13,3 \%)$ có kết quả điêuu trị kém nhiêuu hơn so với bệnh nhân thể lao mới (3,3\%), với p>0,05. Một số nghiên cứu cũng xác định liên quan với kết quả điều trị kém là: xét nghiệm soi đờm tìm AFB (+) là yếu tố nguy cơ độc lập (OR hiệu chỉnh = 1,94) [3]; hang lao (OR, 0,175; CI 95\%, 0,108-0,286, p<0,001) và thời gian điêu trị lao trênmột năm $(O R, 0,077$; 95\%CI, 0,011-0,499, p<0,001) [2].

\section{KẾT LUÂN}

Bệnh nhân RR-TB thường gặp nhiều ở nhóm tuổi trung niên, thể lao cũ, soi đờm có AFB (+), tổn thương Xquang Phổi rộng. Các yếu tố ảnh hưởng đến kết quả điều trị kém là: thể lao cũ, khám phổi có ran, soi đờm có AFB $(+)$, Xquang Phổi có hang.

\section{TÀI LIỆU THAM KHẢO}

1. Bô Y tế, (2018), Hướng dẫn chẩn đoán, điều trị và dự phòng bệnh lao, Quyêt định số 3126/Q' - BYT.

2. Liu CH, Li L, Chen $Z$, Wang $Q$, Hu $Y L$, et al. (2011), Characteristics and Treatment Outcomes of Patients with MDR and XDR Tuberculosis in a TB Referral Hospital in Beijing: A 13-Year Experience. PLoS ONE 6(4): e19399. doi:10.1371/ journal. pone.0019399.

3. Monadil H Ali, et al.2019, "Assessment of multidrug-resistant tuberculosis (MDR-TB) treatment outcomes in Sudan; findings and implications", pp 6.

4. Orina GM, et al., (2017), Comparative Study of Smear Microscopy, Gene Xpert and Culture and Sensitivity Assays in Detection of Mycobacterium tuberculosis on Sputum Samples among Tuberculosis Suspected Cases in Nyamira County Referral Hospital, University Nairobi, Kenya, Mycobact Dis 2017, 7:3 DOI: 10.4172/21611068.1000249.

5. Tang S, Tan S, Yao L, Li F, Li L, et al. (2013), Risk Factors for Poor Treatment Outcomes in Patients with MDR-TB and XDR-TB in China: Retrospective Multi-Center Investigation. PLoS ONE 8(12): e82943.doi:10.1371/journal.pone.0082943

6. WHO (2019), Global tuberculosis report 2019, pp 3,58 .

\section{KHẢO SÁT TƯƠNG QUAN GIỮA KHOẢNG CÁCH GIỮA HAI ĐỒNG TỬ VỚI KHOẢNG CÁCH GIŨ̃A HAI GÓC MẮT TRONG Ở NGƯờI VIÊT TRƯỞNG THÀNH - NGHIÊN CỨU SỬ DỤNG TRONG PHỤC HÌNH Ổ MẮT}

\section{TÓM TẮT}

Mục tiêu: Khảo sát tương quan giữa khoảng cách giữa hai đồng tử với khoảng cách giữa hai góc mắt trong ở người Việt trưởng thành, giúp cung cấp thêm thông tin cho việc thức hiên phục hình ổ mắt, một loai hình trong phục hình hàm mặt. Đối tượng và phương pháp: Nghiên cứu cắt ngang mô tả qua ảnh chụp mặt thẳng của 100 sinh viên khoa Răng Hàm Mặt - Đại học Y Dược thành phố Hồ Chí Minh, tuổi tù̀ 21 đến 28. Dùng phần mềm AutoCAD để đo các kích thước trên ảnh và phân mềm SPSS để phân tích thống kê. Kết quả: Nghiên cứu cho thấy khoảng cách giữa

${ }^{1}$ Đai hoc Y Dước TP. Hồ Chí Minh

Chịu trách nhiệm chính: Nguyễn Thái Phượng

Email: ntphuong@ump.edu.vn

Ngày nhận bài: 18/1/2021

Ngày phản biên khoa học: 21/2/2021

Ngày duyệt bài: 5/3/2021

\section{Nguyễn Thái Phượng ${ }^{1}$ Đoàn Minh Trí}

hai đồng tử có tương quan mạnh với khoảng cách giữa hai góc mắt trong khi xét trên toàn bộ mấu lẫn khi phân chia theo giới $(r>0,5)$. Sử dụng phương trình hồi quy tuyến tính đơn biến giúp dự đoán khoảng cách giữa hai đồng tử từ khoảng cách giữa hai góc mắt trong. Kết luâan: Khoảng cách giữa hai đồng tử có tương quan mạnh với khoảng cách giữa hai góc mắt trong. Có thể dự đoán sơ khởi khoảng cách giữa hai đồng tử từ khoảng cách giữa hai góc mắt trong bằng phương trình hồi quy tuyến tính đơn biến.

Tư khóa: Khoảng cách giữa hai đồng tử, khoảng cách giữa hai góc mắt trong, phục hình ổ mắt.

\section{SUMMARY}

EVALUATION OF THE CORRELATION BETWEEN INTERPUPILLARY DISTANCE AND INTERCANTHAL DISTANCE IN THE ADULT VIETNAMESE - THE STUDY USING FOR OCULAR PROSTHESIS

Objectives: Evaluating the correlation between 